\title{
PEMANFAATAN TEKNOLOGI TEPAT GUNA BERBASIS STRATEGI \\ DIVERSIFIKASI KONSENTRIS UNTUK MENINGKATKAN KUALITAS USAHA PRODUKSI MINYAK CENGKEH
}

\author{
Muhammad Hasan, Sitti Rapika, M. Ihsan Said Ahmad, \\ Tuti Supatminingsih, dan Mustari
}

\begin{abstract}
Program Studi Pendidikan Ekonomi, Fakultas Ekonomi dan Bisnis, Universitas Negeri Makassar, Jl. Raya Pendidikan, Kampus UNM Gunung Sari Baru Makassar, 90222, Indonesia
\end{abstract}

Email: m.hasan@unm.ac.id

\begin{abstract}
ABSTRAK
Strategi bisnis merupakan aspek yang sangat penting dalam menjalankan usaha agar usaha tersebut tetap mampu berkembang dan bersaing secara kompetitif dengan kompetitor sehingga berdampak pada penjualan dan pendapatan usaha. Kajian ini bertujuan untuk mengakaji pemanfaatan teknologi tepat guna berbasis strategi diversifikasi konsentris untuk meningkatkan kualitas usaha produksi minyak cengkeh di Desa Batu Putih Kecamatan Tellu Limpoe, Kabupaten Bone. Jenis kajian ini adalah deskriptif kualitatif dengan jumlah informan sebanyak 3 orang. Teknik pengumpulan data dengan cara observasi, wawancara, dan dokumentasi. Teknik pengabsahan data menggunakan triangulasi sumber. Hasil penelitian ini menunjukkan bahwa kualitas usaha pada produksi minyak cengkeh memakai sistem pengendalian kualitas melalui siklus PDCA, yaitu melakukan perencanaan, pengerjaan atau proses, pengecekan atau evaluasi dan aksi perbaikan. Pada perencanaan (planning), pemilik usaha minyak cengkeh membuat pertimbangan-pertimbangan yang matang dan sesuai dengan standar operasional pelaksanaan (SOP) yang berlaku agar kualitas minyak cengkeh yang akan diproduksi memenuhi kriteria untuk diperjualbelikan. Pada aspek pelaksanaan (doing), pemilik usaha mengikuti pelatihan-pelatihan yang dilakukan oleh dinas terkait peningkatan kualitas dan kuantitas produksi minyak cengkeh. Selanjutnya melakukan studi literasi mengenai inovasi pembuatan minyak cengkeh pada berbagai media mengenai pengolahan minyak cengkeh. Pada aspek pengecekan (checking), pengusaha menetapkan standar produk yang disesuaikan dengan berbagai sumber. Pada aspek tindakan (action), pemilik usaha menyusun kembali prosedur pembuatan minyak cengkeh yang mengalami perbaikan karena adanya perbaikanperbaikan utamanya efisiensi waktu kerja pada unit usaha minyak cengkeh. Hasil dari analisis kualitas produk tersebut meningkatkan kualitas usaha minyak cengkeh di Desa Batu Putih Kecamatan Tellu Limpoe Kabupaten Bone.
\end{abstract}


Kata kunci: Kualitas Usaha, Minyak Cengkeh, Strategi Diversifikasi Konsentris, Teknologi Tepat Guna

\begin{abstract}
A business strategy is a very important aspect of running a business so that the business is able to develop and compete competitively with its competitors, thus impacting on sales and operating revenues. This study aims to assess the use of appropriate technology based on a concentric diversification strategy to improve the quality of clove oil production in Batu Putih Village, Tellu Limpoe District, Bone Regency. This type of study is descriptive qualitative with 3 informants. Data collection techniques by means of observation, interviews, and documentation. The technique of validating the data used source triangulation. The results of this study indicate that the quality of business in clove oil production uses a quality control system through the PDCA cycle, namely planning, working or processing, checking or evaluation and corrective action. In planning, the business owner makes careful considerations in accordance with the applicable operational standards so that the quality of the clove oil to be made meets the criteria and is suitable for sale. In the aspect of doing, clove oil business owners learn by taking part in trainings conducted by related agencies to get maximum results. In addition, reading articles about clove oil manufacturing innovations is also important because it is necessary to upgrade the latest knowledge about clove oil processing. In the checking aspect, entrepreneurs set limits in determining criteria when making clove oil so that the quality of the product made is feasible to be marketed because clove oil is a product that is sought after by consumers. In the aspect of action, the business owner has rearranged the procedure for making clove oil which has undergone improvements due to improvements mainly in working time efficiency of the clove oil business unit. The results of the product quality analysis improved the quality of the clove oil business in Batu Putih Village, Tellu Limpoe District, Bone Regency.
\end{abstract}

Keywords: Appropriate Technology, Business Quality, Clove Oil, Concentric Diversification Strategy

\section{PENDAHULUAN}

Pembangunan dalam perspektif pendekatan kapabilitas secara komprehensif telah mulai menyentuh berbagai aspek kehidupan yang memerlukan pendekatan interdisipliner yang mencakup bidang seperti sosial, ekonomi, pendidikan, budaya, dan politik, karena hal tersebut menyangkut nasib banyak orang (Hasan, 2019; Jacobson \& Chang, 2019). Secara implikatif, pembangunan bertujuan untuk meningkatkan kesejahteraan dan perbaikan kualitas hidup masyarakat dalam konteks yang sangat multidimensional (Tahir \& Hasan, 2018; Fagbemi et al., 2020).

Jika dikaitkan dengan pembangunan dalam perspektif multidimensional, yang meliputi pembangunan ekonomi dan pembangunan manusia, pembangunan dimaknai sebagai proses yang bertujuan untuk membangun hubungan interaksional 
antara sumber daya ekonomi dengan kebutuhan masyarakat yang dalam jangka panjang mampu menciptakan kesejahteraan masyarakat (Soetomo, 2015; Holden \& Christopher, 2018). Pembangunan masyarakat yang bersifat multidimensi penting memperhatikan aspek sumber daya ekonomi secara komprehensif, baik yang berupa sumber daya alam/bahan baku, sumber daya sosial, maupun sumber daya manusia (Bacq \& Eddleston, 2018; Stevens \& De Bruycker, 2020).

Usaha yang terus berkelanjutan dengan keunggulan kompetitif yang dimilikinya, sehingga mampu berkembang dan bersaing dengan kompetitornya dengan berorientasi pada penjualan dan pendapatan yang meningkat, merupakan harapan dari setiap sektor bisnis. Untuk mencapai hal tersebut, setiap usaha penting untuk mengimplementasikan strategi bisnis yang tepat. Lingkungan bisnis yang sangat kompetitif mengharuskan setiap pelaku bisnis yang terlibat agar mampu mendesain strategi yang tepat dan akurat untuk meningkatkan kualitas usahanya (Alexy et al., 2018; Beynon et al., 2020).

Desa Batu Putih, Kabupaten Bone, Provinsi Sulawesi Selatan, merupakadan daerah yang terdapat banyak usaha-usaha yang dikembangkan oleh masyarakat yang dapat meningkatkan kesejahteraan masyarakat. Salah satu usaha tersebut yaitu produksi minyak cengkeh. Hasil observasi awal dilakukan kepada tiga usaha yang memproduksi minyak cengkeh, akan tetapi jumlah produksi belum mencapai produksi hingga 1 (satu) ton per tahun. Padahal jika menilik potensi bahan baku minyak cengkeh yang ada di sekitar Kabupaten Bone sangatlah melimpah. Hal tersebut menunjukkan bahwa proses produksi minyak cengkeh belum dilakukan secara optimal.

Selanjutnya dari hasil wawancara dengan beberapa pengelola usaha minyak cengkeh, proses produksi yang belum optimal berdampak pada produk yang tidak memiliki keunggulan kompetitif di pasar. Pengusaha minyak cengkeh di Desa Batu Putih kesulitan untuk bersaing dan mengembangkan usaha karena terkendala sarana dan prasarana yang dapat mendukung optimalisasi usaha minyak cengkeh. Sementara itu, terdapat beberapa usaha yang dilakukan oleh pengusaha telah kuat secara finansial sehingga dapat berkembang dengan cepat.

Kesulitan-kesulitan yang dialami oleh pihak pengusaha minyak cengkeh di Desa Batu Putih, dapat diatasi salah satunya melalui sistem diversifikasi. Adapun yang dimaksud dengan sistem diversifikasi adalah upaya untuk mengakuisisi usahausaha yang dianggap lambat dan tidak baik dalam pengelolaannya yang dilakukan oleh pelaku usaha yang memiliki finansial dan sumber daya manusia serta pengelolaan usaha yang baik sehingga usaha tersebut dapat berkembang dengan pesat (Putri, 2016). Upaya untuk mendukung pengelolaan usaha yang kompetitif, diperlukan suatu strategi yang dapat meningkatkan keunggulan bersaing produk melalui upaya memfasilitasi pelaku usaha agar mereka secara optimal mampu mengelola sumber daya ekonomi 
lokal dengan kemandirian, khususnya melalui pemanfaatan atau penerapan teknologi secara tepat guna. Pengelolaan sumber daya ekonomi tanpa didukung oleh penerapan teknologi tepat guna yang memadai akan berdampak pada kontribusi sumber daya ekonomi yang kurang optimal dan berkelanjutan, sehingga berdasarkan hal tersebut, pemanfaatan teknologi tepat guna, diyakini merupakan suatu upaya untuk mempercepat pemberdayaan usaha, khususnya bagi usaha kecil, mikro, dan menengah (UMKM) (Yanah et al., 2018).

Hal tersebut berimplikasi pada pentingnya strategi dalam memilih teknologi tepat guna pada UMKM, karena hal tersebut dapat berdampak pada efisiensi biaya produksi, perbaikan kualitas produksi, peningkatan nilai tambah dan kapasitas produk, sehingga UMKM dapat menghasilkan produk yang memiliki standar yang sesuai dengan kebutuhan pasar (Beynon et al., 2020; Hughes et al., 2021). Implikasi dari kajian ini akan melihat peran teknologi tepat guna dalam memberikan aspek positif terhadap peningkatan kualitas produk, sehingga dalam jangka panjang hal tersebut berdampak pada pembangunan dan daya saing desa. Kajian ini bertujuan untuk mendeskripsikan dan menganalisis kualitas usaha minyak cengkeh melalui pemanfataan teknologi tepat guna berbasis strategi diversifikasi konsentris. Strategi ini diimplementasikan melalui penambahan lini produk yang memiliki keterkaitan dengan produk yang tersedia, baik berupa keterkaitan terhadap aspek kesamaan teknologi, penggunaan fasilitas teknologi maupun pemanfaatan jaringan pemasaran secara bersama.

\section{METODE}

Kajian dilaksanakan dengan menggunakan pendekatan kualitatif melalui metode yang bersifat deskriptif kualitatif dan pendekatan research and development (R\&D). Kajian ini dilaksanakan dari bulan September hingga November 2020 bertempat di Desa Batu Putih, Kecamatan Tellu Limpoe, Kabupaten Bone. Subjek yang menjadi informan kajian ini terdiri dari 3 orang pengusaha minyak cengkeh. Dalam kajian ini pengumpulan data menggunakan teknik wawancara, observasi, dan dokumentasi. Analisis data dalam kajian ini menggunakan teknik triangulasi. Penggunaan analisis data triangulasi dalam kajian ini didasari oleh adanya 2 asumsi.

Asumsi pertama adalah dalam perspektif level pendekatan, kajian ini mengkombinasikan dua metode yang saling melengkapi yaitu, pendekatan kualitatif melalui metode yang bersifat deskriptif kualitatif dan pendekatan research and development (R \& D). Untuk mencapai tujuan yang dikehendaki dari kajian ini, masingmasing metode diharapkan dapat saling melengkapi khususnya dalam mengeksplorasi setiap fenomena yang terjadi di lapangan. Fenomena apabila dilihat dalam perspektif metode yang komprehensif, akan menghasilkan eksplorasi yang berbeda, sehingga dengan demikian analisis tringulasi akan memberikan manfaat dalam menggali setiap fenomena secara 
lebih utuh, khususnya yang terkait dengan objek kajian ini.

Asumsi yang kedua adalah dalam perspektif level pengumpulan data, karena pengumpulan dan analisis data dalam kajian ini membutuhkan prosedur yang tepat dan komprehensif, khususnya dalam pengujian dan interpretasi hasil analisis data. Analisis triangulasi dalam kajian ini dapat dilihat pada Tabel 1.

Tabel 1. Analisis Triangulasi

\begin{tabular}{|c|c|c|}
\hline No. & Aspek & Triangulasi \\
\hline 1. & Sumber & $\begin{array}{l}\text { Pakar, pelaku, hasil } \\
\text { kajian sebelumnya, } \\
\text { dan fakta empirik }\end{array}$ \\
\hline 2. & Tujuan & $\begin{array}{l}\text { Adanya skala } \\
\text { prioritas dalam } \\
\text { implementasi } \\
\text { pemecahan masalah }\end{array}$ \\
\hline 3. & Konflik & $\begin{array}{l}\text { Bersama-sama } \\
\text { merumuskan } \\
\text { pemecahan masalah } \\
\text { secara partisipatif. }\end{array}$ \\
\hline 4. & Alat & $\begin{array}{l}\text { Wawancara, } \\
\text { observasi, dan } \\
\text { dokumentasi, serta } \\
\text { pengalaman empirik. }\end{array}$ \\
\hline 5. & Validasi & $\begin{array}{l}\text { Akomodasi } \\
\text { keempat sumber } \\
\text { dalam perspektif } \\
\text { peneliti. }\end{array}$ \\
\hline
\end{tabular}

Konsep kualitas usaha dalam kajian ini dinilai dari kemampuan usaha dalam mengelola usahanya dengan memanfaatkan teknologi tepat guna sebagai upaya meningkatkan peluang usaha dengan berbasis berbasis strategi diversifikasi konsentris. Informan dan subjek dalam kajian ini adalah 3 pengusaha minyak cengkeh dapat dilihat pada Tabel 2.

Tabel 2. Produksi minyak cengkeh Desa Batu Putih tahun 2016-2018

\begin{tabular}{lccc}
\hline \multirow{2}{*}{ Perusahaan } & \multicolumn{3}{c}{ Jumlah produksi (L) } \\
\cline { 2 - 4 } & $\mathbf{2 0 1 6}$ & $\mathbf{2 0 1 7}$ & $\mathbf{2 0 1 8}$ \\
\hline Dinar & $365 \mathrm{~L}$ & $350 \mathrm{~L}$ & $375 \mathrm{~L}$ \\
Mapparessa & $250 \mathrm{~L}$ & $280 \mathrm{~L}$ & $269 \mathrm{~L}$ \\
A. Asaud Rahmat & $350 \mathrm{~L}$ & $450 \mathrm{~L}$ & $415 \mathrm{~L}$ \\
\hline \multicolumn{3}{c}{ Berdasarkan } & \multicolumn{3}{c}{ pendekatan } \\
penelitian, maka & gambaran analisis \\
data triangulasi & dalam kajian ini \\
dapar dilihat pada Gambar 1 (Kaplan \\
$\begin{array}{l}\text { \& Duchon, 1988). } \\
\text { \& }\end{array}$
\end{tabular}
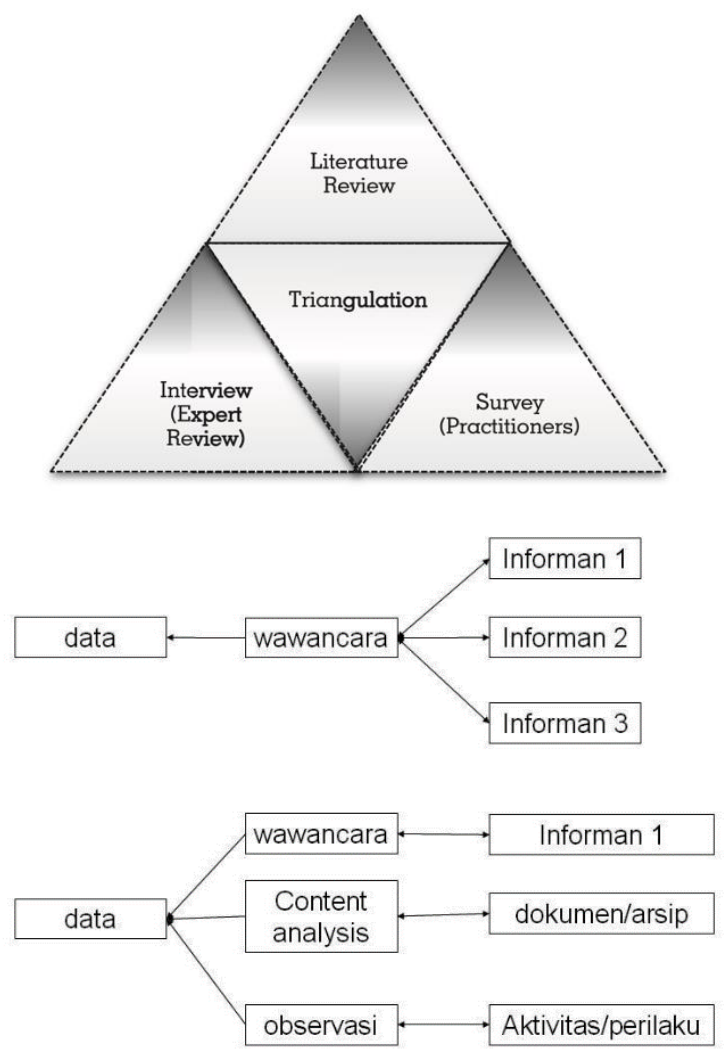

\section{Gambar 1. Teknik Analisis Data}

Kualitas usaha yang dilakukan oleh pelaku usaha dilihat dari penerapan sistem PDCA (Plan, Doing, Check dan Action) dalam kegiatan usahanya yang digambarkan dengan kerangka konseptual pada Gambar 2. 


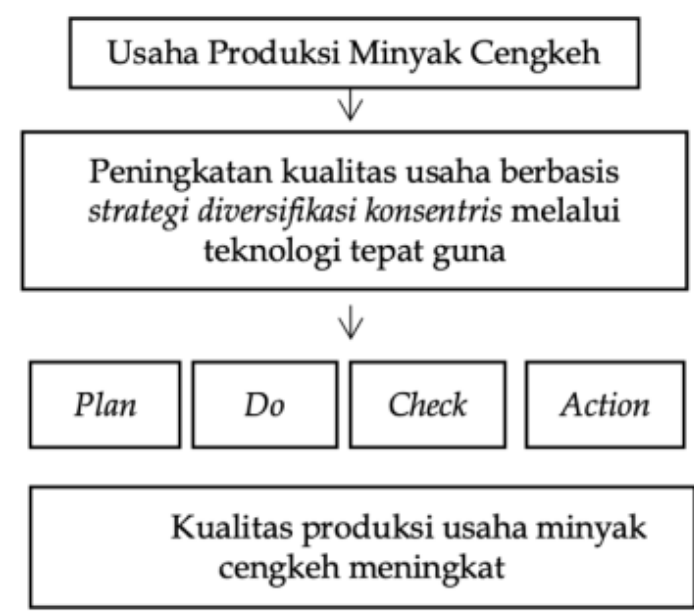

Gambar 2. Skema Kerangka Konseptual

\section{HASIL DAN PEMBAHASAN}

\section{Perencanaan (Plan)}

Pada aspek rencana (planning) produksi minyak cengkeh, pihak pengusaha melakukan proses penentuan perbaikan dengan mengidentifikasi informasi dari pihak karyawan ataupun pada pekerja. Terkait dengan sistem pengelolaannya, dilakukan peninjauan kinerja karyawan serta pembukuan atau laporan keuangan agar sistem manajemen berjalan dengan lancar. Pengusaha juga membuat pertimbangan yang matang dan disesuaikan dengan standar operasional pelaksanaan (SOP) yang berkualitas. Hal ini dimaksudkan agar kualitas minyak cengkeh yang akan dibuat memenuhi kriteria diperjualbelikan. Adapun untuk cara menentukan data dan informasi dalam memilih proses yang paling relevan dengan pembuatan minyak cengkeh adalah dengan berpatokan pada hasil temuan saat proses pembuatan minyak cengkeh.

Untuk penggunaan teknologi tepat guna dalam pembuatan minyak cengkeh, pengusaha pembuat minyak cengkeh dengan menggunakan teknologi tepat guna yang merupakan teknologi yang dapat membantu pengusaha dalam mengefisienkan waktu dan kinerja untuk pembuatan minyak cengkeh. Hasil yang diperoleh pada tahap perencanaan yakni pemilik usaha telah menyusun rencana-rencana strategis dalam mengembangkan usaha berbasis pada tekologi tepat guna berdasarkan hasil analisis dan pengumpulan informasi agar kualitas yang dihasilkan maksimal. Oleh karena itu diperlukan perencanaan yang baik dan sistematis untuk mendapatkan hasil yang lebih baik (Kitsios et al., 2020).

Proses yang menggunakan teknologi yang canggih belum tentu merupakan proses yang dapat menghasilkan kualitas yang lebih baik dalam perspektif konsumen. Produk yang memiliki dan melalui proses yang menggunakan teknologi canggih, namun tidak mengindahkan kebutuhan konsumen akan berdampak pada produk tersebut tidak efisien bagi konsumen, karena berimplikasi pada mahalnya biaya produksi atau harga jual. Pemanfaatan teknologi harus direncanakan dan dipertimbangkan secara seksama khususnya dalam menetapkan target kualitas rancangannya (Dewi \& Maslichan, 2017). Kualitas rancangan yang produk yang baik ditunjukkan oleh dua aspek, yaitu tingginya biaya produksi dan tingginya harga jual.

\section{Pelaksanaan (Do)}

Pelaksanaan (doing) pembuatan minyak cengkeh, pihak pengusaha melakukan pengumpulan informasi 
untuk pembuatan minyak cengkeh dilakukan secara langsung. Pemilik usaha minyak cengkeh belajar dengan ikut pelatihan-pelatihan yang dilakukan oleh dinas terkait sehingga diharapkan mampu menghasilkan output produk yang jauh lebih baik. Selain itu membaca artikel mengenai inovasi pembuatan minyak cengkeh juga penting karena untuk upgrade pengetahuan terkini mengenai pengolahan minyak cengkeh.

Pelaku usaha minyak cengkeh telah menggunakan teknologi tepat guna dalam proses pembuatan minyak cengkeh di usaha pembuatan minyak cengkeh. Hal ini dilakukan agar dapat membantu pelaku usaha dalam meningkatkan efisiensi waktu dan kinerja pada proses produksi minyak cengkeh. Pelaku usaha menjelaskan perubahan proses pembuatan minyak cengkeh pasti akan terjadi. Hal ini terjadi karena perubahan zaman menghadirkan dan menawarkan perubahan-perubahan yang cepat terutama dalam hal teknologi khususnya teknologi penyulingan.

Pelaku usaha menjelaskan bahwa terdapat perubahan yang signifikan dalam proses pembuatan minyak cengkeh. Hal ini terjadi karena kerja penyulingan minyak lebih cepat, efektif dan efisien. Pelaku usaha menjelaskan bahwa jika terdapat kesalahan maka dilakukan perbaikan secara langsung. Hal ini dikarenakan perbaikan penting dalam proses pembuatan minyak cengkeh.

Hasil yang diperoleh pada tahap pelaksanaan yaitu pemilik usaha mengumpulkan informasi mengenai pembuatan minyak cengkeh yang efektif dan efisien menggunakan teknologi tepat guna. Setiap pelaku usaha menjalankan suatu usaha dengan tujuan agar usaha tersebut dapat terus berlanjut, berkembang, dan bersaing dengan kompetitornya sehingga penjualan dan pendapatan diharapkan selalu meningkat (Toelihere, 2014). Selera atau harapan konsumen pada suatu produk selalu berubah sehingga kualitas produk juga harus berubah atau disesuaikan (Kurniawati \& Kusumawati, 2014). Dengan perubahan kualitas produk tersebut, diperlukan perubahan atau peningkatan keterampilan tenaga kerja, perubahan proses produksi dan tugas, serta perubahan lingkungan perusahaan agar produk dapat memenuhi atau melebihi harapan konsumen.

\section{Pemeriksaan (Check)}

Pemeriksaan (checking) produk minyak cengkeh, pihak pengusaha melakukan analisa data-data yang telah terkumpul yang dimaksudkan agar terjadi sinkronisasi ataupun ketepatan data yang diperoleh baik dari laporan keuangan maupun dari proses pelaksanaan pembuatan minyak cengkeh. Selain itu pengusaha juga menetapkan batasanbatasan dalam penentuan kriteria ketika membuat minyak cengkeh. Hal ini berguna agar kualitas produk yang dibuat layak untuk dipasarkan karena minyak cengkeh merupakan produk yang banyak dicari oleh konsumen.

Lebih lanjut, dalam menentukan kualitas minyak, pengusaha minyak cengkeh menggunakan alat ukur yang telah diakui dan memiliki tingkat ketetapatan yang akurat dalam mengukur kadar atau kualitas 
minyak. Secara visual, minyak cengkeh yang baik dapat dilihat dari kejernihan minyak hasil sulingan. Semakin jernih minyak cengkeh yang dihasilkan, semakin baik pula kadar minyak cengkeh tersebut. Adapun minyak cengkeh yang memiliki kualitas kurang baik biasanya tetap dijual ke pengepul atau konsumen meskipun minyak kualitas rendah memiliki harga yang rendah juga. Hal ini dikarenakan minyak yang memiliki kadar kualitas rendah tetap memiliki harga di pasaran sehingga pengusaha minyak cengkeh tidak merugi.

Hasil yang diperoleh dari tahap pemeriksaan (check) yaitu pemilik usaha telah menggunakan standar atau kriteria-kriteria tertentu dalam menentukan kualitas minyak cengkeh yang dihasilkan. Pemeriksaan menggunakan analisis dan alat yang lebih canggih dan modern. Hasil tersebut sesuai dengan pendapat (Priatma, 2013) yang menyatakan bahwa setiap pelaku usaha perlu mengidentifikasi alat yang dapat mengatasi permasalahan dalam menjalanakan proses produksi karena semakin kompetitifnya lingkungan bisnis. Pelaku usaha diharapkan memiliki produk atau pelayanan yang berkualitas baik dan tinggi sehingga mampu memiliki nilai kompetitif. Kualitas yang baik hanya dapat dihasilkan oleh pelaku usaha yang memiliki sistem manajemen kualitas yang handal (Saidani \& Arifin, 2012).

\section{Tindakan (Action)}

Pada tahap tindakan (action) atau tindakan pemilik usaha menyusun kembali prosedur pembuatan minyak cengkeh yang mengalami perbaikan dilakukan oleh ketiga pengusaha minyak cengkeh tersebut. Peyusunan tersebut dilakukan karena adanya perbaikanperbaikan, terutama efisiensi waktu kerja pada unit usaha minyak cengkeh. Selain itu, kapasitas produksi juga semakin banyak dan memiliki kualitas bagus karena telah dikerjakan meggunakan mesin canggih. Sementra itu, prioritas pengusaha dalam melakukan perbaikan ditentukan oleh seberapa penting dan mendesaknya kesalahan yang dilakukan oleh pemilik usaha.

Selain itu, dilakukan analisis terlebih dahulu untuk melihat aspek yang paling untuk dilakukan perbaikan karena hal tersebut akan berpengaruh pada proses produksi minyak cengkeh. Di lain sisi, pemilik usaha mengajarkan pembuatan minyak cengkeh kepada karyawannya. Pembelajaran yang dilakukan dalam bentuk pelatihan atau melihat secara langsung cara membuat minyak cengkeh yang kemudian ditirukan oleh karyawan. Tiap karyawan memiliki porsi kerja yang berbeda menyesuaikan tahapan kerja dalam membuat minyak cengkeh.

Tahapan ini berimplikasi pada pentingnya menyesuaikan aspek perencanaan dengan aspek implementasi. Pada tahapan ini, temuan menunjukkan bahwa terdapat beberapa perbedaan antara hal-hal yang direncanakan dengan hal-hal yang dilaksanakan. Perbedaan antara perencanaan dan pelaksanaan tersebut bukanlah merupakan hal yang keliru, namun menjadi hal yang penting untuk diperhatikan 
khususnya dalam melakukan rencana tindak lanjut.

Hasil yang diperoleh dari tahap tindakan (action) yakni pemilik usaha menyusun kembali prosedur pembuatan minyak cengkeh yang mengalami perbaikan dilakukan oleh ketiga pengusaha minyak cengkeh tersebut. Peyusunan tersebut dilakukan karena adanya perbaikanperbaikan utamanya efisiensi waktu kerja pada unit usaha minyak cengkeh. Perbaikan-perbaikan tersebut penting untuk dilakukan agar setiap kelompok usaha, utamanya yang berada di daerah pedesaan dapat menjadi lokomotif penggerak pembangunan dan roda perekonomian pedesaan (Tambunan, 2013). Pemanfaatan sumber daya manusia dengan mengajarkan langsung kepada karyawan mengenai pembuatan minyak cengkeh merupakan salah satu bentuk dari pembangunan masyarakat pedesaan sehingga dapat memberdayakan masyarakat pedesaan dengan efektif.

\section{KESIMPULAN}

Kualitas usaha pada pembuatan minyak cengkeh memakai sistem pengendalian kualitas dengan memutarkan siklus PDCA, yaitu melakukan perencanaan, pengerjaan atau proses, pengecekan atau evaluasi dan aksi perbaikan. Pada perencanaan (planning), pemilik usaha membuat pertimbanganpertimbangan yang matang dan sesuai dengan standar operasional pelaksanaan (SOP) yang berlaku agar kualitas minyak cengkeh yang akan dibuat memenuhi kriteria dan layak untuk diperjualbelikan.
Pada aspek pelaksanaan (doing), pemilik usaha minyak cengkeh belajar dengan ikut pelatihan-pelatihan yang dilakukan oleh dinas terkait untuk mendapatkan hasil yang lebih maksimal. Selain itu membaca artikel mengenai inovasi pembuatan minyak cengkeh juga penting karena untuk upgrade pengetahuan terkini mengenai pengolahan minyak cengkeh.

Pada aspek pengecekan (checking), pengusaha menetapkan batasan-batasan dalam penentuan kriteria ketika membuat minyak cengkeh agar kualitas produk yang dibuat layak untuk dipasarkan karena minyak cengkeh merupakan produk yang banyak dicari oleh konsumen.

Pada aspek tindakan (action), pemilik usaha menyusun kembali prosedur pembuatan minyak cengkeh yang mengalami perbaikan karena adanya perbaikan-perbaikan utamanya efisiensi waktu kerja pada unit usaha minyak cengkeh. Hasil dari analisis kualitas produk tersebut meningkatkan kualitas usaha minyak cengkeh di Desa Batu Putih Kecamatan Tellu Limpoe Kabupaten Bone.

\section{DAFTAR PUSTAKA}

Alexy, O., West, J., Klapper, H., \& Reitzig, M. (2018). Surrendering Control to Gain Advantage: Reconciling Openness and the resource-Based View of the Firm. Strategic Management Journal, 39(6), 1704-1727. https:// doi.org/10.1002/smj.270 6

Bacq, S. \& Eddleston, K.A. (2018). A Resource-Based View of Social 
Entrepreneurship: How Stewardship Culture Benefits Scale of Social Impact. Journal of Business Ethics, 152(3), 589-611. https://doi.org/10.1007/s10551016-3317-1

Beynon, M. J., Jones, P., \& Pickernell, D. (2020). SME Development Strategy and Product/Service Innovation Intention: A NCaRBS Analysis of the Role of Uncertainty. The International Journal of Entrepreneurship and Innovation, 21(1), 3-16. https:/ / doi.org/10.1177/1465750 318807401

Dewi, D. A. L., \& Maslichan. (2017). Upaya Peningkatan Kualitas Produksi dan Manajemen Usaha Pada UMKM Genteng dan Batu Bata. Jurnal pengabdian Pada Masyarakat (PENAMAS), 1(1), 3442.

Fagbemi, F., Oladejo, B., \& Adeosun, O. A. (2020). The Effectiveness of Poverty Alleviation Policy: Why Is the Quality of Institutions the Bane in Nigeria?. Review of Development and Change, 25(2), 215-236.

https:/ / doi.org/10.1177/0972266 120975262

Hasan, M. (2019). Characteristic of Human Development: Socioeconomic Dimension. KnE Social Sciences, 3(11), 865-874. https:/ / doi.org/10.18502/kss.v3i 11.4055

Holden \& Christopher. (2018). Global Social Policy: An Application of Welfare State Theory. Journal of International and Comparative Social Policy, 34(1), 40-57. https:/ / doi.org/10.1080/2169976 3.2017.1413993

Hughes, M., Hughes, P., Morgan, R. E., Hodgkinson, I. R., \& Lee, Y. 2021. Strategic Entrepreneurship Behaviour and the Innovation Ambidexterity of Young Technology-based Firms in Incubators. International Small Business Journal: Researching Entrepreneurship, 39(3), 202-227. https:/ / doi.org/10.1177/0266242 620943776.

Jacobson, T. \& Chang, L. (2019). Sen's Capabilities Approach and the Measurement of Communication Outcomes. Journal of Information Policy, 9(1), 111-131. https://doi.org/10.5325/jinfopol i.9.2019.0111

Kaplan, B., \& Duchon, D. (1988). Combining Qualitative and Quantitative Methods in Information Systems Research: A Case Study. MIS Quarterly, 12(4), 571-586. https://doi.org/10.2307/249133.

Kitsios, F., Kamariotou, M. \& Talias, M. A. (2020). Corporate Sustainability Strategies and Decision Support Methods: A Bibliometric Analysis. Sustainability, 12(2), 521. https://doi.org/10.3390/su12020 521.

Kurniawati, D., \& Kusumawati, S. A. (2014). Pengaruh Citra Merek Dan Kualitas Produk terhadap Kepuasan dan Loyalitas Pelanggan (Studi Pada Pelanggan Kfc Cabang Kawi Malang). Jurnal Administrasi Bisnis (JAB), 14(2), 19. 
Putri, R., L. (2016). Peningkatan Kualitas Produk Melalui Penerapan Prosedur dan Sistem Produksi: Studi Pada UD Wijaya Kusuma Kota Blitar. Wahana Riset Akuntansi, 4(2), 813-827. https:/ / doi.org/10.24036/wra.v4 i2.7223

Priatma, D. (2013). Strategi Komunikasi Lembaga Pemberdayaan Masyarakat (LPM) dalam Sosialisasi Program Pembinaan Masyarakat di Kelurahan Loa Bakung Kota Samarinda. Ejournal Ilmu Komunikasi Fisip Unmul, 1(2), 7084

Saidani, B., \& Arifin, S. (2012). Pengaruh Kualitas Produk dan Kualitas Minat Beli Pada Ranch Market. Jurnal Riset Manajemen Sains Indonesia (JRMSI), 3(1), 1-22.

Soetomo. (2015). Pemberadayaan Masyarakat: Mungkinkah Muncul Antitesisnya. Yogyakarta: Pustaka Pelajar.

Stevens, F., \& De Bruycker, I. (2020). Influence, Affluence and Media Salience: Economic Resources and Lobbying Influence in the European Union. European Union Politics, 21(4), 728-750.

https:/ / doi.org/10.1177/1465116 520944572

Tahir, T. \& Hasan, M. (2018). Poverty's Characteristics and its Reduction Strategies: A Case Study, European Research Studies Journal, 21(2), 426-440.

https:/ / doi.org/10.35808/ersj/1

012
Tambunan, T. (2013). Pola Pembangunan Ekonomi di Pedesaan. Jakarta: PT Pustaka LP3ES Indonesia.

Toelihere, M. (2014). Pengantar, Pengembang dan Penyebarluasan Teknologi Tepat Guna. Jakarta: Dirktorat Jenderal Pendidikan Tinggi Depertemen Pendidikan dan Kebudayaan.

Yanah, Y., Nakhwatunnisa, H., \& Sukarno, T.A. (2018). Strategy to Increase the Competitiveness of SME's Entreprises. JEJAK: Jurnal Ekonomi dan Kebijakan, 11(1), 138150.

https:/ / doi.org/10.15294/jejak.v 11i1.11705 